Journal of Engineering and Applied Sciences 14 (8): 2485-2491, 2019

ISSN: 1816-949X

(C) Medwell Journals, 2019

\title{
An Acoustic Psychological Analysis of a Sound of Dadeumi using an Acoustics Analysis
}

\author{
${ }^{1} \mathrm{Ik}$-Soo Ahn, ${ }^{1}$ Myung-Jin Bae and ${ }^{2}$ Seong-Geon Bae \\ ${ }^{1}$ Department of Information and Telecommunication, Soongsil University, \\ 369 Sangdo-ro, Dongjak-gu, Seoul, Korea \\ ${ }^{2}$ School of Software Application, Kangnam University, Gyunggi-do, Korea
}

\begin{abstract}
As a study on the effect of sound on the human body we conducted an acoustic psychological analysis on the sound of dadeumi. It is a research that puts a well-folded fabric on a stone and puts a cloth on the bat and spreads the wrinkles. The sound is bright and clear and makes you feel better. The reason why the pleasant sound is caused by what reason is examined through the material of the tool and how to use it. In addition, the sound components were analyzed by acoustic analysis and acoustic psychological analysis was performed using EEG analysis and Morse test. The tool is a set of plastered stones and two batts. The plastered stones are made of marble and the bats are made of birch. Scratchy looks like a banging action that creates a jolly rhythm and the intensity is controlled to play a musical instrument. Acoustically, the low frequency of less than $1,000 \mathrm{~Hz}$ and the sound of $3,000 \sim 4,000 \mathrm{~Hz}$ band are harmoniously suitable for the psychological response of the person. EEG analysis showed that EEG spectrographs with higher intracranial pressure frequencies were formed in the order of exoskeleton and twinning rather than rhythm. In the Morse test, the more the rhythm and harmony were produced by the rhythm than the simple rhythm sound, the higher the psychological response was. Sounds generated by traditional Korean tools as well as musical instruments must be studied in the future.
\end{abstract}

Key words: Dadeumi's quality, dadeumistone, dadeumi bat, dadeumi's material, usage method, acoustic analysis, EEG analysis

\section{INTRODUCTION}

The dadeumi sound was introduced to the people of the world as one of the sound themes of Korean tradition at the 1988 Seoul Olympics opening ceremony. The reason why I chose the sound of Korean guitars as the original sound theme at the opening ceremony of the Olympic games was because the beauty of the beat and the melody showed the emotion and response of the Korean people, although, the clear and clean tone could be charm. Older Korean souls regarded the sound of plucking as one of three kinds of play sounds. Three kinds of play soundsmean three sounds that make people happy. The three sounds were: first a baby crying; second, a book reading; baby crying means honoring the prosperity of descendants who can be generous and the sound of reading a book means that the richness of mind through study is high. But the third dadeumi sound was included in those three precious sounds but when I heard the sound of dadeumi, the sound was so, clear and blue that I nodded my head. The reason why we include the sound of dadeumiin the sound of play is that it is important not only for the clarity and clarity of the sound of the scissor but also for the stability of life through diligence and cleanliness. If you listen to the sound of dadeumi like you are playing a musical instrument why am I enjoyable, happy and excited? It is because of the inherent percussive musical elements with musical instruments and rhythmic qualities which are our unique traditional life tools. Perhaps that is why many of our own traditional musical instruments are percussion instruments. Bok, janggu, kangkari, jing, the bell are representative traditional percussion instruments. Although, not a musical instrument in real life if there is a tool to match a percussion instrument like a percussion instrument there is a sound of a pruning sound a threshing thorn a wood ax and a smith sound. Among them there are tools that are unique to Korea and made by living wisdom. In this study, we investigate the musical tendency by the beat and melody in order to investigate

Corresponding Author: Myung-Jin Bae, Department of Information and Telecommunication, Soongsil University, 369 Sangdo-ro, Dongjak-gu, Seoul, Korea 
the reason why it was chosen as one of Sam-Hee Sung. First, we analyze the principle of sound generation by examining the material and the method of use of the tools used in the quality improvement. Next, the sound generated by the musical instrument was analyzed by acoustic analysis and the acoustic psychology was analyzed through the brain wave and moss test of the celadon listening to the sound (Jae-Hoon, 2000; Bae et al., 2013; Choi, 2005; Kim, 2015).

\section{MATERIALS AND METHODS}

Dadeumi: The dadeumi bat is a life tool that consists of a basic set of dadeumi stones and a pair of bats. Since, ancient times, our ancestors were a people who enjoyed beauty and taste with their diligent character, so, they licked grass on the cloth and wrinkled them and neatly dressed them. I used a variety of shapes and sizes of phials to stretch out the garments but I had to do it to make it easier to stretch and straighten the fabric before making it. We examined the material, form and usage of the tool to make a dadeumi.

The dadeumi tool consists of a dadeumistone and a bat. The "plastered" stone was made by cutting solid granite stones into a rectangular shape with a suitable size of about 50-70, 20-25 and 15-20 cm in height. The upper part of the "plaster" stone was quenched smoothly to protect the fabric and the center part was raised, so that, the "plastering" effect was enhanced. The lower part of the stone curtain made a space that resonates, so that, the sound can be made by making a leg shape or by making a space with the bottom surface of the ship. The pluck bat is made of birch or ash tree and has a diameter of $4 \sim 5 \mathrm{~cm}$ and a length of $35 \sim 40 \mathrm{~cm}$. The dadeumibat made the surface smooth, making it thicker to touch the stone and thinner to hold the hand grip (Choi, 2005; Kim, 2015; Shin et al., 2005).

The dadeumi quality which has been handed down from ancient times is a lifestyle tool that parents use in rural areas. In the era when the profession is well developed like now a days, we will buy clothes and leave laundry to the laundry. Who will say that we will do the dadeumibut there are still many mothers who are doing scapegoat in the countryside. The traditional method of making the suede is to dry the pumekin fabric first then wrap it on the thick red cloth and knock it over. The fabric that has been tapped for a long time is released again, the water is poured into the mouth and it is folded into the size of a dadeumi stone and wrapped in a wrapping cloth several times. The fabric, thus, prepared is placed on a dadeumistone and patted evenly with a dadeumibat. Basically, dadeumiis mainly made by one person, sometimes by two people. It is said that one person of dadeumi is called single and two is couple. The two pairs of dadeumi qualities are tied to each other, so, they do not interfere with the quality of the batting quality of the other party. In a house when the sound of a pair of dadeumi sounds, the mother-in-law and her daughter-in-law come face to face with each other in a friendly manner. A cloth made in this way is smoother than ironing and does not get wrinkled (Kyoung and Jin, 2015; Bae and Kim, 2013 and Hoon and Myung, 2007).

\section{RESULTS AND DISCUSSION}

Psychological analysis of dadeumi sound: Figure 1 and 2 the sound quality is pure, clear and light. The hard dadeumistone and the dadeumibat made of wood bump against each other with a moderate thickness of cloth to make a sound which filters the rough and sharp sounds and resonates at the bottom of the gypsum stone. It happens the reason why people feel the sound of dadeumi is clear and light because the frequency band that people feel psychologically is a lot. One or two pairs of bats alternate slowly, fast, strong and weakly stroking the dadeumistone, so, it sounds like playing percussion. In addition, middle-aged and older adults say that when they listen to the sound of dadeumi they feel emotionally reminiscent of their mother in their hometowns and that they will also miss their nostalgic nostalgia and their deceased father.

Those who have grown up to see the dadeumi will naturally remember the old sentiment. It is expected that if you tell the story about this kind of dadeumi quality you will get a comfortable and stable sound psychological effect emotionally even if the generation has not heard the dadeumi quality sound. We will show youths and children the old dadeumi quality tools and how to use them, show pictures and videos, let them know how to use them and experience them and they will share similar emotions with adults. When you show a movie in the old days, sometimes you see a scene of dadeumi up and young people can experience indirect experiences, narrowing the emotional gap between generations. In order to analyze the acoustic psychology of the dadeumi voiced sound, acoustic analysis and EEG analysis were performed (Shin et al., 2005; Bae and Kim, 2013; Jeong and Bae, 2007; Song et al., 2011 and Ahn and Bae, 2017).

The sound of a dadeumisound is a sound that makes your mind clear and intelligent and makes you feel 
(a)

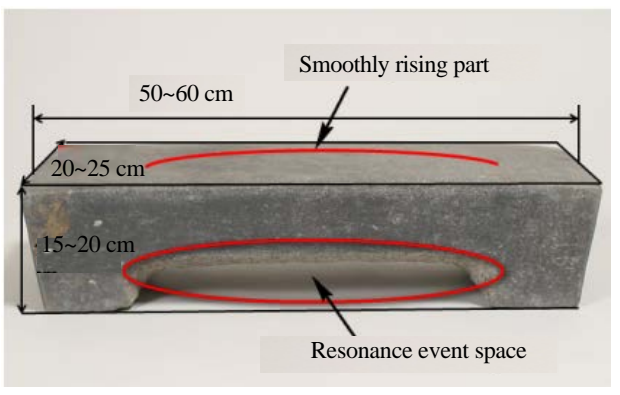

(b)

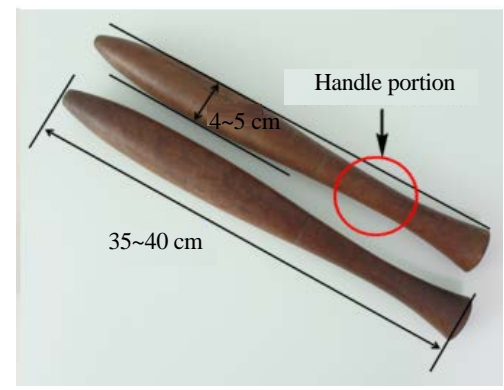

Fig. 1: Dadeumi stone and dadeumi bat; a) Dadeumi stone and b) Dadeumi bat

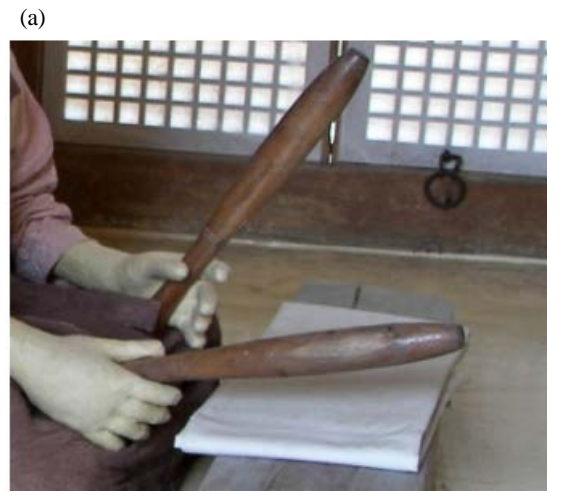

(b)

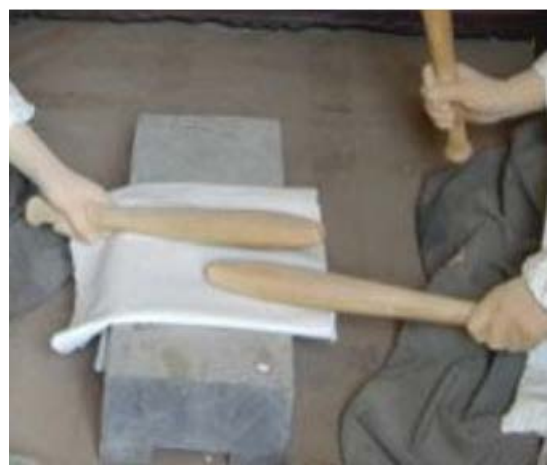

Fig. 2: Dadeumi appearance; a) Single dadeumi and b) Couple dadeumi

cheerful. What kind of sound ingredient makes you feel such a feeling. We can infer from experience that a clear and clean sound will result in a clear tone when hard stones and resilient wooden bats hit each other. Also, it is predicted that the lightness can be derived from the method of knitting a stone with a bat. In order to analyze the sound energy, sound characteristics and sound composition of dadeumi quality sound, we performed the acoustic analysis. We used time domain analysis to analyze the composition of sound, spectrogram analysis to analyze negative energy and spectrum analysis to analyze sound characteristics. For the acoustic analysis, we sampled the dadeumi quality sound by dividing it into a sound of tapping without a rhythm an external dadeumi quality sound and a pair of dadeumi quality sound. A cool editor was used for the analysis tool. The sample rate was set to $44,100 \mathrm{~Hz}$, the channel was set to Mono and the resolution was set to 16 bits. We analyzed the components of sound in the time-domain graph to prove the reality of the sound quality. The time domain graph is a method of analyzing the structure of the dadeumi sound to be analyzed by grasping the waveform and frequency of sound per a certain time.
The three time-domain graphs in Fig. 3 analyzed the sound components within $5 \mathrm{sec}$ in order to confirm rhythm and melody of dadeumi by examining the frequency and intensity per time of dadeumi bat. To compare the sound components of the dadeumi sound a sound sample of a dadeumi bass sound, a, b Dadeumi sound and a, c couple dadeumi sound without a rhythm was converted into a time domain graph. First, a time-domain graph of a rhythmical bat without a rhythm can be seen as simply tapping a stone with a single bat at the same interval at the same interval. On the other hand, if we look at the time domain graph of the dadeumi sound other than $b$, we can see that the rhythm is played for $5 \mathrm{sec}$ in the 8th, 1st, 5th, 1st and 3rd times. Finally, it can be seen that the time domain graph of the couple dadeumi sound changes the beat to 4 times in the strong intensity format and 4 times in the strong intensity format and 3 times in the strong intensity format. The above graphs are divided into $5 \mathrm{sec}$ in order to compare three sounds in detail but rhythm and melody can be more clearly distinguished when they are heard longer. The spectrogram graph was analyzed in order to check the sound energy of each dadeumi sound. This analysis is an 
(a)

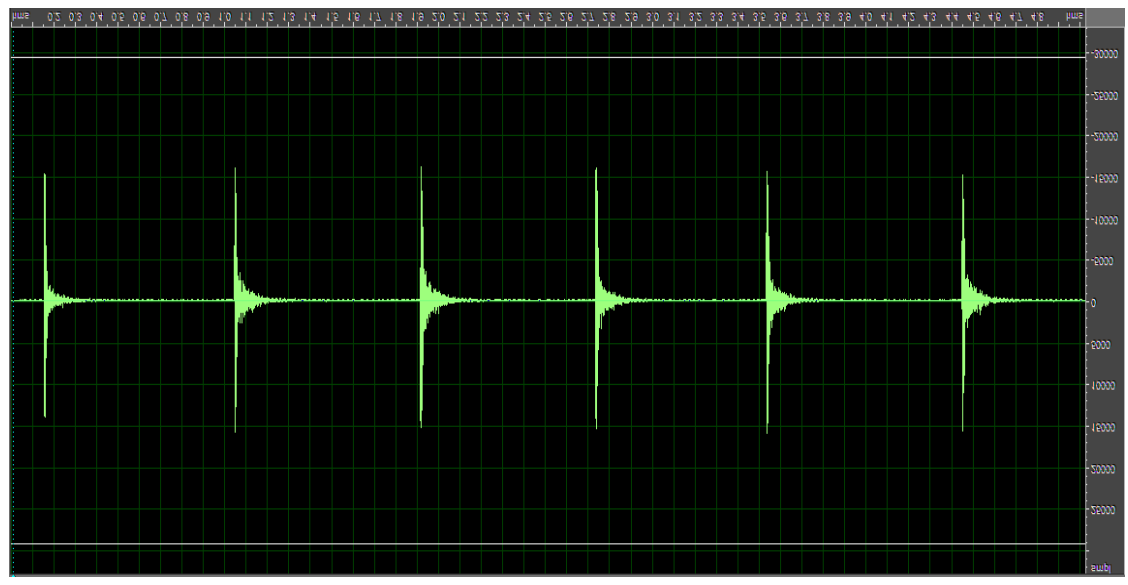

(b)

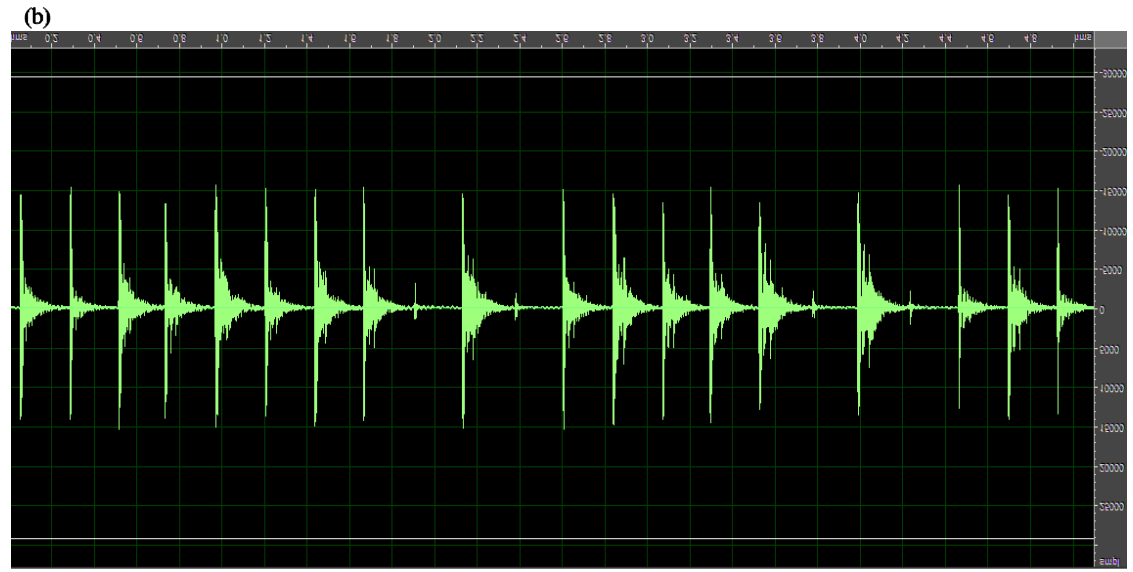

(c)

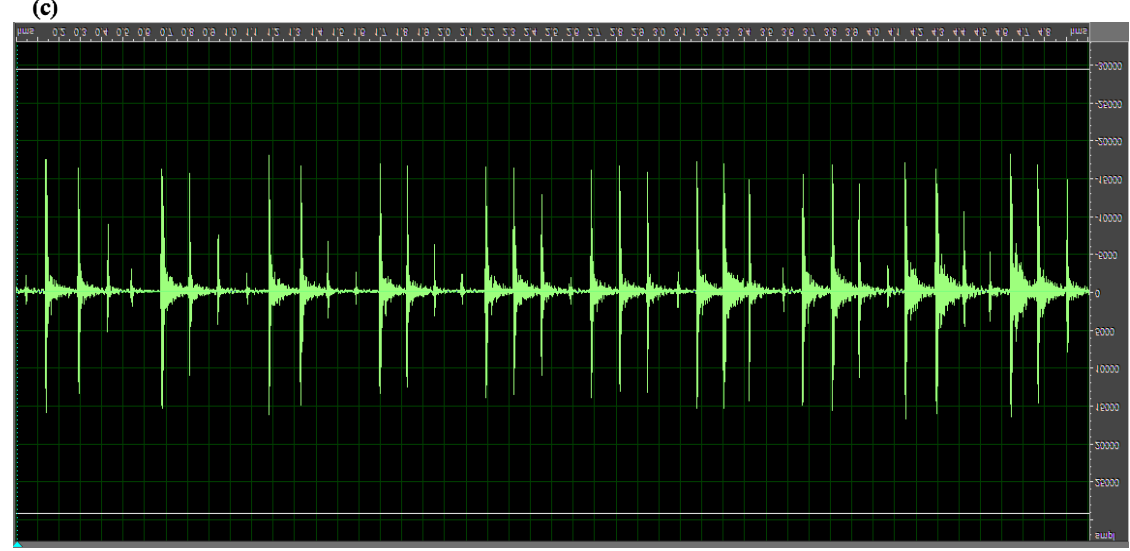

Fig. 3: Time-domain graph of dadeumiquality sound; a) Rhythm-free dadeumi bats time zone graph; b) Time-domain graph of single dadeumi quality sound and c) Time-domain graph of couple dadeumi quality sound

analysis that is used as data for predicting the psychoacoustic sensation felt by a person by confirming where the distribution of the energy constituting the sound is mainly distributed in the audio frequency band (Fig. 4).
The results show that the three kinds of drowsiness sounds differed from the acoustical analysis and showed different results in the electroencephalogram and moss test. From the acoustical point of view according to frequency analysis, the strongest energy was generated 


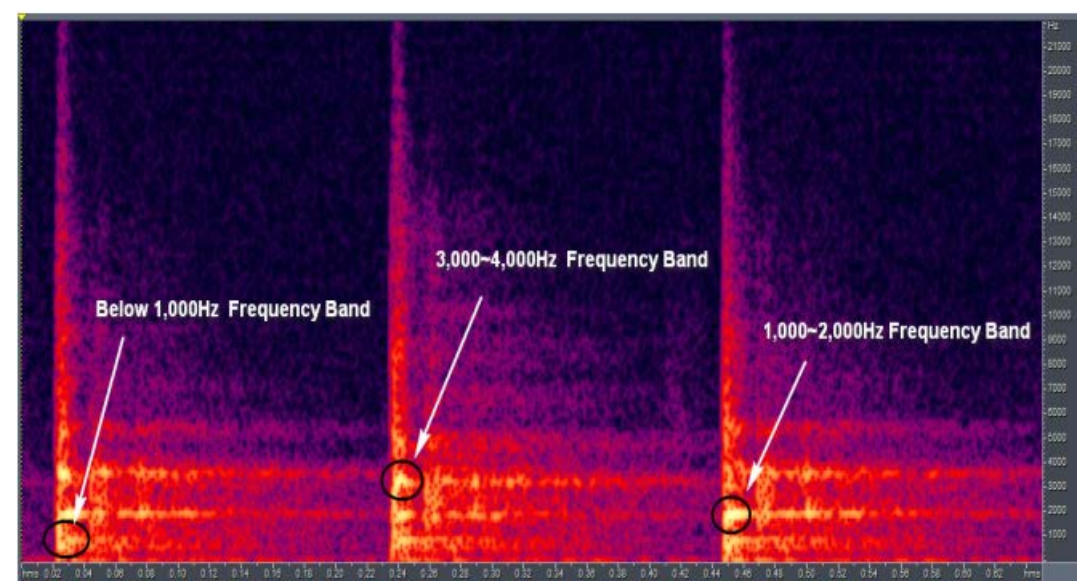

Fig. 4: Spectrogram graph of dadeumi sound

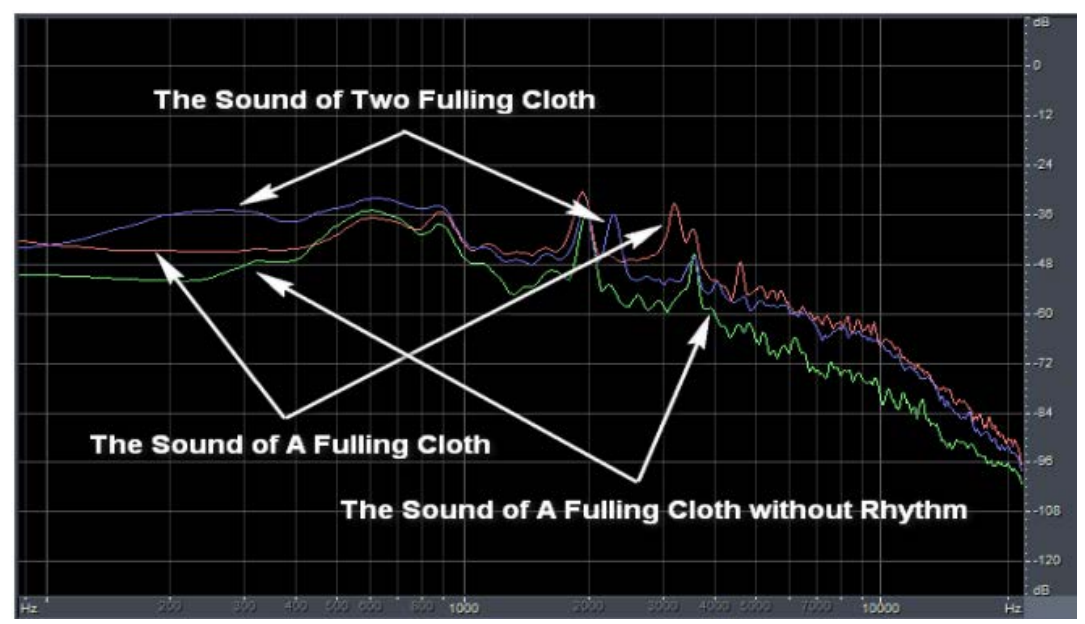

Fig. 5: Spectrum graph comparative analysis of dadeumi sound

intensively and the sound that stimulated the auditory was the whistle sound but in the EEG and Morse test we were most strongly imprinted in everyday life and strongly responded to the impressive sound of the siren It is seen. As a result, it was suggested that the sound for eliminating drowsiness should be selected not only by the acoustic analysis but also by choosing or creating a sound in harmony with the emotion. Of course, it was judged that the sound-damping sound that is currently, operating in the highway tunnel studied through this study is very effective. In order to check the sound energy of frequency of "Tannery" sound, I tried to check the spectrogram graph by sampling the sound of tapping 3 times with dadeumi stone on the stone with dadeumi bat ignoring rhythm and melody. In the energy distribution diagram of the dadeumi sound in Fig. 4, the energy source is divided into 3 parts. The first is widely distributed in the low frequency band below $1,000 \mathrm{~Hz}$, the second is strongly distributed in the central part of the $1,000-2,000 \mathrm{~Hz}$ band and the third is strongly distributed in the center part of the 3,000-4,000 Hz band. As shown in the graph of the energy distribution through the spectrogram of the dadeumi sound, "finish" sound can be confirmed that the energy is distributed in the most comfortable sound band in the human's audio frequency band.

The dadeumi quality sound has a weak peak up to $400 \mathrm{~Hz}$ even in the low frequency band below $1,000 \mathrm{~Hz}$, and only two peak points are formed, one at $2,000 \mathrm{~Hz}$ and one at $3,000 \mathrm{~Hz}$, even in the high frequency band above 
(a)

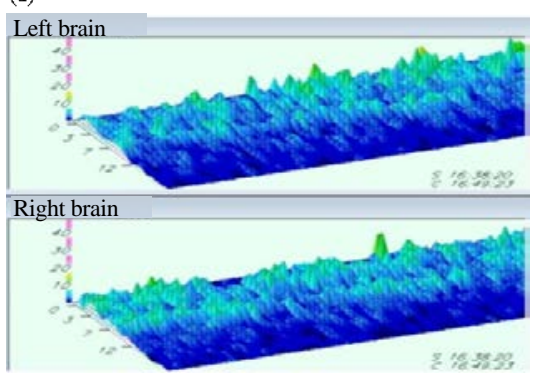

(b)

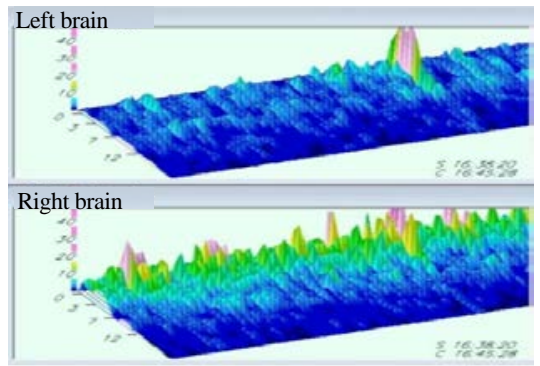

(c)

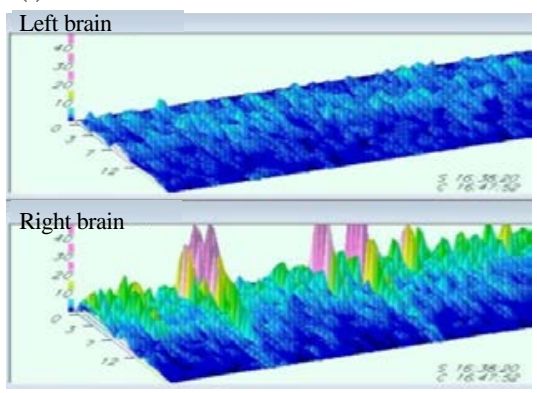

Fig. 6: EEG when listening to three dadeumi; a) When I listen to the sound of a dadeumibat without rhythm; b) EEG when listening to dadeumi and c) EEG when listening to couple dadeumi

Table 1: Sound psycho-modal test for dadeumi sound

\begin{tabular}{lllllll}
\hline Variables & A & B & C & D & E & Average \\
Rhythm-free sound & 2 & 1 & 1 & 2 & 1 & 2.3 \\
Single dadeumi & 4 & 3 & 4 & 3 & 3 & 5.6 \\
Couple dadeumi & 5 & 4 & 5 & 5 & 5 & 8 \\
\hline
\end{tabular}

$1,000 \mathrm{~Hz}$. The sound of dadeumi which is taped by one person is higher than that of dadeumi in a low frequency band below $1,000 \mathrm{~Hz}$ or high frequency band above $1,000 \mathrm{~Hz}$. The most notable change is that peak peaks in the high frequency band above $1,000 \mathrm{~Hz}$ have increased from two to three and are beginning to vary. The dadeumi sound of two people sitting opposite to each other was the highest in the low frequency band below $1,000 \mathrm{~Hz}$ and the two broad peaks were formed. In the high frequency band above $1,000 \mathrm{~Hz}$ there are three distinct peak peaks. It can be seen that peak points are formed. Comparing these phenomena it can be seen that as the rhythmic sensation is formed, rhythmic sensation is formed as rhythmic sensation is formed, the volume becomes richer in both low frequency and high frequency bands and the frequency peaks and peak points become various and become various shapes (Fig. 6 and Table 1).

In order to analyze the acoustic psychology that responds to the dadeumi sound we measured and analyzed the brain waves. The sound of the plucking sound was measured by listening to each of the three sound sources such as a rhythm-free plucking sound, a dadeumi and a pair of dadeumi. In order to make reliable EEG measurement for each dadeumi sound, we closed the eyes and listened to the sound of the musculoskeletal at the same time and performed EEG measurement. When you open your eyes and measure the EEG, the movement of the brain becomes distracted while watching the objects around you. To measure the EEG correctly, you should close your eyes and concentrate on the sound.

First, the EEG measured while listening to the tapping sound of the dadeumi bat without rhythm showed an EEG spectrogram graph showing a flat ICP frequency without any special reaction. Next when the EEG sounds of the dadeumi sound are seen an EEG spectrograph is being drawn which shows the smooth and pleasant waves of the alpha and beta waves of the right and left brain waves. When we look at the EEG spectrograph measured by listening to a pair of dadeumi sounds we can see that the changes in the ICP frequency of the alpha and beta waves are occurring in the right brain. The brain waves of dadeumi sound were more responsive to the right brain which is responsible for emotions than the changes of the left brain and the reaction was greater in dadeumi and tone than in rhythm and rhythm.

\section{CONCLUSION}

Dadeumi is one of the unique living works of ours using tools made of dadeumistones and bats. The method of dadeumiis to fold the cloth to be fulled on the dadeumistone and tap it with two bats. The sound is clear, clear and cheerful which makes the listener happy. Acoustic analysis of the dadeumi showed that they had a strong energy sound component in the 3 frequency 
bands where people were most sensitive. The EEG analysis showed that the alpha and beta waves are activated when people feel awake and feel cheerful. Through the mos test to find the acoustic psychology of the dadeumi sound we also obtained the psychological response of the pair with the dadeumi sound which has rhythm and melody from the dadeumi sound to the harmony. The sound also makes dadeumi in the home where it is learned through direct and indirect experience and makes the emotional feel comfortable by reminding the mother. The light rhythm, melody and harmony of the dadeumi sound are thought to be worthy of being used as a sound to relieve stress by giving a pleasant and pleasant response. At the opening ceremony of the 1988 Olympic games in Seoul when many students came out to harmonize with the sound of dadeumi, the world was impressed by the fantastic, subtle and cheerful sound.

\section{RECOMMENDATIONS}

In the future, it is expected that it will be an important research to produce another Korean wave content using sound by making sound contents by not only a sound of dadeumi but also sounds of Korean life tools. In the future, we will investigate the sound characteristics of Korean traditional tools of life and investigate the changes of the human body in response to the sound thereby relieving stress and improving mood. We should continue to study the sound of healing.

\section{REFERENCES}

Ahn, I.S. and M.J. Bae, 2017. On a foley sound content of the birds song. Intl. Inf. Inst. Tokyo Inf., 20: 917-922.

Bae, M. and M. Kim, 2013. Professor Bae's Sound Story. Gimm-Young Publishers, Seoul, South Korean,
Bae, S., M. Kim and M. Bae, 2013. On enhancement signal using non-uniform sampling in clipped signals for LTE smart phones. Proceedings of the ICCE Berlin 2013 IEEE 3rd International Conference on Consumer Electronics Berlin (ICCE-Berlin'13), September 9-11, 2013,EEE, Berlin, Germany,ISBN:978-1-4799-1412-8, pp: $129-130$.

Choi, E.J., 2005. The sound of trimming. Lit. Spring Festival, 12: 72-75.

Hoon, H.S. and J.B. Myung, 2007. A study on the sound enhancement of concentration. IEICE., 30: 671-672.

Jae-Hoon, S., 2000. The validity of legal regulations on the use of mobile phones during driving. Taipei Non-Life Insurance Association, Taipei, Taiwan.

Jeong, C.J. and M.J. Bae, 2007. A study on the classification of amazing sounds. Acoust. Soc. Korea, 26: 57-58.

Kim, G.J., 2015. The sound of scissors. Times Essay, 10: 210-212.

Kyoung, S.Y. and B.M. Jin, 2015. Psychoacoustic study of automobile engine sound. Acoust. Soc. Korea, 34: 180-180.

Shin, Y.G., H. Shin and C. Kook, 2005. A questionnaire research on subjective sound recognition. Trans. Korean Soc. Vibr. Eng., 15: 558-563.

Shin, Y.G., S. Hoon, K. Chan and S.W. Kim, 2013. A comparison study on auditory scenery for sound environment improvement in Traditional Korean style housing (Han-ok) style housing villages in Jeollanam-do. J. Korean Soc. Rural Plann., 19: 63-73.

Song, M.J., K. Shin-Hoon, K. Kwang-Gon and G. Ho-Gon, 2011. A basic study on the characteristics of the electroencephalogram corresponded with the evaluating words of soundscape sound source. J. Korean Soc. Ecol. Environ., 11: 49-56. 